\title{
Bruxismo: uma abordagem genética
}

\section{Bruxism: a genetic approach}

\author{
Patrícia Cataldo de Felipe Cordeiro ${ }^{1}$ \\ LETÍCIA LADEIRA BONATO² \\ VALQUIRIA QUINELATO 1 \\ Priscila Ladeira CASAdo ${ }^{1}$
}

\begin{abstract}
RESUMO
Introdução: Bruxismo é definido como uma atividade repetitiva dos músculos mastigatórios caracterizada pelo ranger e/ou apertar de dentes com diferentes manifestações circadianas. Objetivos: A complexa fisiopatologia e a variedade de distúrbios associados justificam a busca por delineamentos específicos sobre fatores etiológicos individuais. A obtenção de dados genético-moleculares para estudo da possível relação entre genética e bruxismo foram foco de investigação do estudo, por meio de uma revisão de literatura. Material e métodos: As bases de dados consultadas foram Pubmed, BVS e Scielo, no período de 1998 a 2018. Conclusão: A relação genética foi demonstrada como parcialmente hereditária, considerando sujeitos gêmeos. Alterações polimórficas em genes das vias dopaminérgica e seratoninérgica também foram relacionadas com bruxismo.
\end{abstract}

Palavras-chave: Bruxismo; dopamina, genética

\begin{abstract}
Introduction: Bruxism is defined as a repetitive activity of masticatory muscles characterized by tooth grinding with different circadian manifestations. Objectives: The complexy physiopathology and variety of associated disorders justify a detailed knowledge about individual ectiological factors. Thus, the present study aimed to elucidate the relationship relationship between genetic and bruxism through a literature review. Material and methods: The databases consulted were PubMed, BVS and Scielo in the 1998 a 2018. Conclusion: The genetic relationship was show to be partially hereditary, considering twin subjects. Polymorhisms in the dopaminergic and seratoninergic pathway genes was associated with bruxism.
\end{abstract}

Keywords: Bruxism; dopamin, genetic

${ }^{1}$ Faculdade de Odontologia, Universidade Federal Fluminense, Niteróı, Rio de Janeiro, Brasil

${ }^{2}$ Faculdade Estácio de Sá, JuIz de Fora, Minas Gerais, Brasil 


\section{INTRODUÇÃO}

O bruxismo é definido como uma atividade repetitiva dos músculos mastigatórios caracterizada pelo ranger e/ou apertar de dentes ${ }^{1}$, apresentando-se durante o sono e/ ou em vigília. De fisiopatologia desconhecida, o bruxismo em vigília (BV) tem prevalência de $20 \%$ na população. Já o bruxismo do sono (BS), prevalente em $8 \%$ da população, é associado a microdespertares relacionados ao sono com aumento da carga cardíaca autonômica e atividade respiratória ${ }^{2}$.

O comportamento mostrou associação com diversos distúrbios caracterizando sua complexa fisiopatologia ${ }^{3}$. Ambas as manifestações circadianas do bruxismo refletem características psicológicas específicas como ansiedade, sensibilidade ao estresse e padrões excitatórios ${ }^{3-5}$. O BS ainda se apresenta associado a síndrome da apneia obstrutiva do sono, síndrome das pernas inquietas e refluxo gastroesofágico ${ }^{6}$. A ingestão de substâncias como álcool, tabaco, cafeína e alguns antidepressivos também apresentam influência no desenvolvimento do bruxismo ${ }^{7,8}$.

Efeitos prejudiciais oriundos desse comportamento mostram-se como justificativa para condutas de controle. Desgastes dentários, fraturas de reabilitações protéticas, exacerbação de dores orofaciais, sensibilidade dentária, cefaleia tensional temporal e ruídos sonoros durante o sono são consequências observadas em bruxômanos ${ }^{2}$. De modo adicional, os efeitos estendem-se aos familiares e/ou companheiros de quarto que experimentam distúrbios do sono devido à privação ocorrida por ruídos sonoros de cisalhamento ${ }^{9}$.

Durante décadas, a etiologia do bruxismo baseou-se em fatores morfológicos periféricos. Contudo, o foco presente estende-se aos fatores fisiopatológicos centrais associados a alterações em neurotransmissores e suas vias $^{10}$, especificamente as vias dopaminérgicas e seratoninérgicas ${ }^{8,10,11}$, excluindo a influência de fatores periféricos como discrepâncias oclusais e alterações ósseas orofaciais ${ }^{12,13}$. Neste contexto, alterações genéticas em receptores específicos foram relacionadas ao desenvolvimento bruxismo ${ }^{11}$.

Duas hipóteses foram descritas para justificar a participação da neurotransmissão dopaminérgica e serotoninérgica na gênese e modulação do bruxismo: a teoria hiperdopaminérgica e a teoria hipodopaminérgica ${ }^{14,15}$. Os estados hiperdopaminérgicos são caracterizados por hipersensibilidade dos receptores e podem ser induzidos pela utilização de anfetaminas, ecstasy e cocaína, assim como durante o uso de levodopa em casos de doença de Parkinson. Nestes indivíduos, pode-se desenvolver o ranger de dentes durante a vigília e o sono ${ }^{15,16}$.

Apesar de ser evidente a neurofisiologia na origem dos episódios de bruxismo, não se sabe explicar especificamente como são gerados os movimentos oromandibulares involuntários a partir da neurotransmissão das catecolaminas. A dopamina destaca-se na influência da neurotransmissão central, uma vez que é predominante no sistema extrapiramidal dos mamíferos e de várias vias neuronais, mesocorticais e mesolímbicas, e apresenta, entre outras, a função de inibir os movimentos espontâneos. Dessa maneira, uma disfunção dopaminérgica da projeção nigroestriada poderia induzir a comportamentos estereotipados e locomotores, como ocorre nos episódios de bruxismo ${ }^{17}$. Dessa forma, ressalta-se a possibilidade da influência de fatores genéticos individuais na etiologia da disfunção dopaminérgica e sensibilidade de receptores.

Jáahipótesehipodopaminérgicaéjustificada pelo uso de antidepressivos inibidores seletivos da recaptação de serotonina (ISRS). Este grupo de drogas é responsável pela inibição 
de forma potente e seletiva da recaptação de serotonina, resultando em potencialização da neurotransmissão serotonérgica, posto que aumenta a disponibilidade da serotonina na fenda sináptica ${ }^{7}$. O aumento da transmissão serotoninérgica induzida pelos ISRS por sua vez, produz uma redução dopaminérgica nos circuitos mesocortical e nigroestriatal, que ativa o córtex pré-frontal, causando automatismos oromandibulares e ranger de dentes ou próteses durante o sono ${ }^{8,15}$.

Dessa forma, devido à complexidade da condição e a variedade de distúrbios associados ressalta-se a necessidade de um conhecimento detalhado sobre possíveis fatores individuais a fim de direcionar condutas específicas para consequências do bruxismo. A obtenção de dados genético-moleculares das vias dopaminérgica e seratoninérgica de indivíduos bruxômanos, durante ou sono ou vigília possibilitaria o delineamento da fisiopatologia do comportamento, sugerindo que alterações genéticas possam influenciar os movimentos mandibulares esteoritipados ${ }^{11}$. Portanto, o presente estudo busca elucidar essa relação por meio de uma revisão de literatura.

\section{Material e mÉtodos}

Trata-se de um estudo de revisão narrativa na qual não utiliza critérios sistemáticos para a busca e análise crítica da literatura. A abordagem metodológica permitiu a construção de uma contextualização da problemática e a análise das possibilidades presentes na literatura consultada para a concepção do referencial teórico da pesquisa.

A seleção de artigos foi realizada no banco de dados PubMed (US National Library of Medicine), BVS e Scielo por meio dos descritores "bruxism AND genetic". A seleção foi realizada no período de 1998 a 2018. (Figura 1).
Todos os estudos que evidenciaram algum tipo de participação genética na gênese do bruxismo foram incluídos de forma a identificar a possível influência de fatores genéticos no desenvolvimento da condição. Foram excluídos do estudo artigos duplicados e inadequados ao objetivo do estudo como abordagens de outras desordens de movimento e distúrbios do sono.

Para complementar a pesquisa, realizouse uma busca manual nas listas de referências bibliográficas dos trabalhos incluídos, com o intuito de localizar outros artigos relevantes para fundamentação teórica da modalidade de tratamento em estudo.



Figura 1 - Fluxograma: Seleção e inclusão dos artigos do estudo.

\section{REVISÃo dE LITERATURA}

\section{Evidências genéticas}

As primeiras evidências genéticas de bruxismo buscaram elucidar a hereditariedade do comportamento. Estudos constataram que de $20 \%$ a $50 \%$ de indivíduos diagnosticados apresentaram, pelo menos, um membro imediato de sua família com a mesma 
parafunção ${ }^{18,19}$. Neste contexto, considerando que o bruxismo é concomitante com outras condições expressas em doentes, dificilmente estaria associado com a expressão ou a alteração de um único gene, sugerindo uma influência poligênica².

A influência genética no bruxismo também foi evidenciada por estudos de concordância. Concordância é a presença da mesma característica fenotípica em pares de gêmeos geralmente monozigóticos. Um estudo de concordância envolve a análise de dados de concordância para estabelecer se uma condição (nesse caso, bruxismo) é mais prevalente em gêmeos monozigóticos ou dizigóticos. Se a concordância da condição de interesse é significamente maior em monozigóticos, a herediariedade participa do desenvolvimento ou perpetuação daquela condição. A base para essa conclusão é que monozigóticos são geneticamente idênticos, enquanto dizigóticos compartilham somente $50 \%$ do material genético ${ }^{9}$. Assim como em estudos familiares, a maioria dos estudos de gêmeos concluíram que o bruxismo é parcialmente determinado por fatores genéticos ${ }^{20,21}$.

Atualmente questiona-se a provável relação de alterações psicológicas, como o estresse, na expressão gênica do sistema nervoso autônomo ou vias excitatórias do sistema nervoso central, que são responsáveis pela atividade motora oral e desenvolvimento de bruxismo ${ }^{2}$. Entretanto, autores defendem que não há evidências de que as expressões de genótipos característicos de indivíduos com personalidade ansiosa poderiam influenciar o desenvolvimento de bruxismo. Esses genótipos têm sido observados e estudados em outras doenças relacionadas com este tipo de personalidade ${ }^{22-24}$.

Ressalta-se assim a participação de genes candidatos na atuação da expressão gênica e homeostase de neurotransmissores. Dentre eles, destaca-se os genes relacionados com o transporte e receptação de serotonina, os quais estão associados ao quadro de personalidade ansiosa ${ }^{24}$. Uma das alterações do gene-receptor de serotonina SLC6A4 mais estudados é o polimorfismo 5-HTTLPR, o que corresponde a uma variação genética em que uma inserção ou deleção de um fragmento de 44 pares de bases que ocorre no gene alvo. A alteração resulta em redução da atividade de transcrição e aumento da susceptibilidade a perturbações afetivas. Funcionalmente, esta variável está associada com inibidores da recaptação da serotonina diminuída ${ }^{25}$. Nesse contexto, desequilíbrios na recaptação de serotonina exercem uma influência indireta sobre o sistema dopaminérgico, o que pode ser evidenciado quando usuários de ISRS, após uso prolongado, desenvolvem bruxismo ${ }^{26}$.

Entretanto, muitas limitações reduzem a probabilidade de encontrar genes diretamente associados com bruxismo. O auto relato da manifestação em familiares próximos ${ }^{18,19}$, adicionado à hipótese poligênica indica um percurso inicial em relação aos fatores etiológicos genéticos. Do mesmo modo, é difícil isolar a influência do estresse e ansiedade na sequência de ativações de genes e proteínas gerando efeitos excitatórios cerebrais ${ }^{2}$.

Até o momento nenhum marcador genético foi identificado para o BS, entretanto estudos relataram que $21-50 \%$ dos pacientes apresentam um membro da família com o mesmo comportamento ${ }^{2}$. Em indivíduos infantis, outro estudo mostrou que 20 de 39 crianças bruxômanas apresentam pelo menos um parente que exiba o mesmo comportamento ${ }^{18}$.

Um estudo de caso-controle que evidencioua relação entre fatores genéticos e o metabolismo de serotonina encontrou uma variante particular do gene HTR24 no cromossomo 13, associada a codificação de recptores. A variante foi relacionada com aumento de risco de $B S$, sugerindo que fatores genéticos contribuem para essa condição ${ }^{27}$. No entanto, o estudo não explorou essa relação com outra manifestação circadiana do bruxismo.

Dessa forma, um estudo recente buscou avaliar a frequência de polimorfismos 
genéticos da mesma via estudando BS e BV. Os resultados corroboraram o estudo anterior evidenciando associação entre o polimorfismo do gene HTR2A rs2770304 com aumento do risco de desenvolvimento de $\mathrm{BS}^{11}$, ressaltando a necessidade de novas pesquisas para esclarecimento de sua fisiopatologia.

Genes da via dopaminérgica também mostraram participação na gênese do BV em estudo pioneiro, o qual buscou explorou a contribuição de variantes genéticas desta via para o desenvolvimento do bruxismo considerando ambas manifestações circadianas, isoladas ou conjuntas. Polimorfismos nos genes DRD2 rs1800497 e $D R D 5$ rs6283 foram relacionados a redução de risco de $\mathrm{BV}^{10}$. (Tabela 1)

Tabela 1 - Evidências científicas da influência genética no bruxismo

\begin{tabular}{|c|c|c|c|c|c|}
\hline Autor & Ano & Amostra & Análise genética & Gene & Resultados \\
\hline $\begin{array}{l}\text { Hublin } \\
\text { et al. }{ }^{20}\end{array}$ & 1998 & $\begin{array}{c}1298(M Z) \\
e \\
2419(D Z)\end{array}$ & $\begin{array}{l}\text { Estudo de gêmeos - } \\
\text { Variância fenotípica }\end{array}$ & & $\begin{array}{c}\text { Alta correlação entre o bruxismo } \\
\text { na infância e em adultos } \\
\text { conferindo efeito genético } \\
\text { substancial. }\end{array}$ \\
\hline $\begin{array}{l}\text { Abe et } \\
\text { al. }{ }^{27}\end{array}$ & 2012 & 120 & Polimorfismo & $\begin{array}{l}\text { SLC6A4, } \\
\text { HTR1A, } \\
\text { HTR2A e } \\
\text { HTR2C }\end{array}$ & $\begin{array}{c}\text { HTR2A - O alelo C (rs6313 - } \\
102 \mathrm{C}>\mathrm{T} \text { ) foi associado com } \\
\text { aumento de risco de bruxismo do } \\
\text { sono, }\end{array}$ \\
\hline $\begin{array}{l}\text { Rintakoski } \\
\text { et al. }{ }^{21}\end{array}$ & 2012 & 3126 & $\begin{array}{c}\text { Estudo de gêmeos } \\
\text { - Decomposição da } \\
\text { variância fenotípica } \\
\text { em: efeitos genéticos } \\
\text { aditivos (A), efeitos } \\
\text { genéticos dominantes } \\
\text { (D) e efeitos } \\
\text { ambientais não } \\
\text { compartilhados (E). }\end{array}$ & & $\begin{array}{l}\text { Os efeitos genéticos aditivos } \\
\text { representaram } 52 \% \text { ( } 95 \% \mathrm{Cl} 0.41- \\
\text {-0.62) da variância fenotípica } \\
\text { total de bruxismo do sono, sem } \\
\text { diferenças entre gêneros. }\end{array}$ \\
\hline $\begin{array}{l}\text { Oporto } \\
\text { et al. }{ }^{11}\end{array}$ & 2016 & 130 & Polimorfismo & HTR2A & $\begin{array}{l}\text { Polifmordismo no gene HTR2A } \\
\text { rs2770304 está associado } \\
\text { com aumento do risco de } \\
\text { desenvolvimento de bruxismo do } \\
\text { sono }\end{array}$ \\
\hline $\begin{array}{l}\text { Takaoka } \\
\text { et al. }\end{array}$ & 2017 & $\begin{array}{c}108 \\
\text { gêmeos }\end{array}$ & $\begin{array}{l}\text { Estudo de gêmeos - } \\
\text { Variância fenotípica }\end{array}$ & & $\begin{array}{c}\text { Os efeitos genéticos aditivos } \\
\text { podem ser um fator contribuinte } \\
\text { para a ocorrência de atividade } \\
\text { de EMG noturna associada ao } \\
\text { bruxismo do sono. }\end{array}$ \\
\hline $\begin{array}{l}\text { Oporto } \\
\text { et al. }^{10}\end{array}$ & 2018 & 130 & Polimorfismo & $\begin{array}{l}D R D 1 \\
D R D 2, \\
D R D 3 \\
D R D 4 \\
D R D 5 \\
\text { MAOB }\end{array}$ & $\begin{array}{c}\text { Polimorfismos nos genes } D R D 2 \\
\text { rs1800497 e DRD } 5 \text { rs6283 foram } \\
\text { relacionados a redução de risco } \\
\text { de bruxismo em vigília. }\end{array}$ \\
\hline $\begin{array}{l}\text { Cruz-Fierro } \\
\quad \text { et al. }^{34}\end{array}$ & 2018 & 171 & Polimorfismo & HTR2A & $\begin{array}{c}\text { Nenhuma diferença significativa } \\
\text { foi encontrada na associação } \\
\text { entre pacientes com bruxismo } \\
\text { (sono, vigília ou combinado) e } \\
\text { o polimorfismo no gene HTR2A } \\
\text { (rs6313) } \\
\end{array}$ \\
\hline
\end{tabular}




\section{INFLUÊNCIA DE FATORES AMBIENTAIS}

Menciona-se o papel da epigenética no potencial de expressão ou inibição gênica para o desenvolvimento de bruxismo em pessoas submetidas a estresse e ansiedade ${ }^{28}$. Os traços individuais de personalidade estão associados à atividade de vias de neurotransmissores específicos $^{29}$.

A ciência da epigenética estuda alterações químicas que regulam a expressão gênica. Existem dois tipos principais de mecanismos epigenéticos: os que modificam a molécula de DNA diretamente e os que afetam a cromatina, complexo que a molécula de DNA forma com algumas proteínas, principalmente as histonas ${ }^{30}$. A metilação consiste na adição de um radical metil $(\mathrm{CH} 3)$ no carbono 5 da base nitrogenada citosina feita por enzimas DNA-metil-transferases (DNMTs). A metilação do DNA leva ao recrutamento de proteínas que causam a compactação da cromatina, impedindo que a enzima RNA-polimerase se ligue à molécula inibindo expressão gênica ${ }^{30,31}$. Manifestações de bruxismo foram associadas a síndrome de Rett, causada por mutações no gene que codifica a DNMT sugerindo associação entre desregulação epigenética e bruxismo ${ }^{31}$.

Como para o estresse e ansiedade, altos níveis de catecolaminas foram relacionados com o desenvolvimento de movimentos oromandibulares ${ }^{17,32}$. Elevados níveis de catecolaminas foram detectados na urina de bruxômanos em comparação com os pacientes sem o comportamento, sugerindo que 0 estresse e a ansiedade poderiam ser fatores etiológicos, em parte, para o desenvolvimento do BS.

Contudo, a literatura ainda não apresenta informações específicas sobre a influência da epigenética no bruxismo, como uma expressão exacerbada ou inibição de determinados genes implicaria no desenvolvimento da condição em pessoas submetidas a estresse e/ou outros estímulos ambientais ${ }^{28}$.

\section{Discussão}

Inicialmente, a abordagem genética do bruxismo direcionava-se ao estudo da hereditariedade da comportamento, mostrando que a condição era compartilhada por membros imediatos da mesma família ${ }^{18,19}$. Neste contexto, considerando que o bruxismo é concomitante com outros distúrbios, torna-se possível a associação com a expressão e/ou alteração poligênica².

Uma predisposição genética pode explicar o aparecimento de BS na infância e sua provável persistência ao longo da vida ${ }^{27}$. Polimorfismos genéticos de nucleotídeo único envolvidos na neurotransmissão serotonérgica foram associados significativamente com um risco aumentado de $B^{11,27}$. Este tipo de polimorfismo pode induzir uma função reduzida dos receptores de serotonina e, em seguida, uma ação serotoninérgica excessiva ${ }^{11}$. Esta ação leva a um déficit dopaminérgico, que causa uma forma específica de movimentos mandibulares estereotipados, como no $\mathrm{BS}^{14}$.

A íntima associação do bruxismo com alterações psicológicas, como o estresse, torna-se questionável sua relação com a expressão gênica de vias excitatórias do sistema nervoso central, que são responsáveis pela atividade motora oral e desenvolvimento de bruxismo ${ }^{2}$ como as vias dopaminérgicas e seratoninérgicas.

Dessa forma, buscou-se relacionar os fatores genéticos, o metabolismo de serotonina e o desenvolvimento de bruxismo do sono. A variante do gene HTR2A - (rs6313 - 102C > T) foi associado com aumento de risco de BS, sugerindo a contribuição de fatores genéticos ${ }^{27}$. No entanto, o estudo não explorou essa relação com outra manifestação circadiana do bruxismo, explorada por um estudo recente 
o qual avaliou a frequência de polimorfismos genéticos em BS e BV. O polimorfismo do gene HTR2A (rs2770304) também foi associado ao aumento do risco de BS ${ }^{11}$.

Seguindo a hipótese da relação do bruxismo com a via dopaminérgica, os também mostraram participação na gênese do bruxismo, em estudo pioneiro, o qual também explorou a contribuição de variantes genéticas considerando ambas manifestações circadianas, isoladas ou conjuntas. Polimorfismos nos genes DRD2 (rs1800497) e DRD5 (rs6283) foram relacionados a redução de risco de $\mathrm{BV}^{10}$.

A influência genética do bruxismo foi relatada em literatura por muitos estudos de gêmeos de concordância ${ }^{18,19,33}$ os quais concluíram que a condição é, no mínimo, parcialmente hereditária. Embora, o resultado corrobore com estudo familiar $^{19}$, existe a possibilidade de o relato ser apenas por manifestação de comportamento com deficiência na pureza do diagnóstico. Contudo, estudos gêmeos e/ou familiares não puderam elucidar os mecanismos fisiológicos envolvidos do bruxismo. Isso requer análise de DNA - o método utilizado apenas em quatro estudos recentes ${ }^{10,11,27,34}$.

Até o momento, poucos estudos buscaram evidenciar especificamente a contribuição genética para etiologia do bruxismo. Ressaltase a necessidade de maiores evidências sobre a predisposição genética para o BS, de forma que o diagnóstico seja conduzido não só por questionários e exame clínico, mas por testes genéticos e medicina personalizada. Desse modo, terapias preventivas para complicações associadas ao bruxismo do sono estariam disponíveis para indivíduos geneticamente predispostos.

\section{Conclusão}

A relação genética foi demonstrada como parcialmente hereditária, considerando sujeitos gêmeos. Alterações polimórficas em genes das vias dopaminérgica e seratoninérgica também foram relacionadas com bruxismo. Contudo, ressalta-se a necessidade da ampliação do campo de pesquisa genéticomolecular para delineamento específico de mecanismos associados e/ou desencadeantes, possibilitando, portanto, diagnósticos e tratamentos precisos.

\section{REFERÊNCIAS}

1. Lobbezoo F, Ahlberg J, Glaros AG, Kato T, Koyano K, Lavigne GJ et al. Bruxism defined and graded: an international consensus. J Oral Rehabil. 2013;40:2-4. doi: 10.1111/joor.12011.

2. Lavigne GJ, Khoury S, Abe S, Yamaguchi T, Raphael K. Bruxism physiology and pathology: an overview for clinicians. J Oral Rehabil. 2008;35:476-494. doi: 10.1111/j.1365$-2842.2008 .01881 . x$.

3. Manfredini D, Arreghini A, Lombardo L, Visentin A, Cerea S, Castroflorio T et al. Assessment of coping and anxiety features in bruxers: a portable EMG/ECG study. J Oral Facial Pain Headache. 2016;30:249-254. doi: 10.11607/ ofph.1616.

4. Manfredini D, Fabbri A, Peretta R, Guarda-Nardini L, Lobbezoo F. Influence of psychological symptoms on homerecorded sleep-time masticatory muscle activity in healthy subjects. J Oral Rehabil. 2011;38:902-911. doi: 10.1111/j.1365$-2842.2011 .02226 . x$

5. Manfredini D, Lobbezoo F. Role of psychosocial factors in the etiology of bruxism. J Orofac Pain. 2009;23:153-166. https://www.ncbi.nlm. nih.gov/pubmed/19492540

6. Mengatto CM. Dalberto Cda S, Scheeren B, Barros SG. Association between sleep bruxism and gastroesophageal reflux disease. J Prosthet Dent. 2013;110:349-355. 10.1016/j.prosdent.2013.05.002.

7. Uca AU, Uğuz F, Kozak HH, Gümüş H, Aksoy $F$, Seyithanoğlu A et al. Antidepressant-induced sleep bruxism: prevalence, incidence, and related factors. Clin Neurophar- 
macol .2015;38:227-230. doi: 10.1097/ WNF.0000000000000108.

8. Cordeiro PCF, Bonato LL, Ferreira LA, Carvalho ACP. Inibidores seletivos da recaptação da serotonina e bruxismo: associação em usuário de prótese total. Revista Saúde e Pesquisa.2014;7(3):553-61. http://periodicos. unicesumar.edu.br/index.php/saudpesq/article/ view/3557/2498

9. Lobbezoo F, Visscher CM, Ahlberg J, Manfredini D. Bruxism and genetics: a review of the literature. J Oral Rehabil. 2014;41: 709-714. doi: 10.1111/joor.12177.

10. Oporto GH, Bornhardt T, Iturriaga V, Salazar LA. Single nucleotide polymorphisms in genes of dopaminergic pathways are associated with bruxism. Clin Oral Investig. 2018;22(1):331-337. doi: 10.1007/ s00784-017-2117-z.

11. Oporto GH, Bornhardt T, Iturriada V, Salazar LA. Genetic polymorphisms in the serotoninergic system are associated with circadian manifestations of Bruxism. J Oral Rehabil. 2016;43(11):805-812. doi: 10.1111/ joor.12436.

12. Lobbezoo F, Naeije M. Bruxism is mainly regulated centrally, not peripherally. J Oral Rehabil. 2001;28(12):1085-91. https://www.ncbi. nlm.nih.gov/pubmed/11874505

13. Morais DC, Oliveira AT, Monteiro AA, Alencar MJS. Bruxismo e sua relação com o sistema nervoso central: Revisão de Literatura. Rev. bras. odontol. 2015; 72 (1/2):2-5. http://revista.aborj.org.br/index.php/rbo/article/download $/ 585 / 458$

14. Lavigne GJ, Rompré PH, Poirier G, Huard $\mathrm{H}$, Kato T, Montplaisir JY. Rhythmic masticatory muscle activity during sleep in humans. J Dent Res. 2001;80(2):443-8. https://www.ncbi.nlm. nih.gov/pubmed/11332529

15. Alóe F, Gonçalves LR Azevedo A, Barbosa RC. Bruxismo durante o sono. Revista Neurociências. 2003; 11 (1): 4-17. http://www.revistaneurociencias.com.br/edicoes/2003/RN\%2011\%20 01/Pages\%20from\%20RN\%2011\%2001.pdf

16. Falisi G, Rastelli C, Panti F, Maglione H, Quezada Arcega R. Psychotropic drugs and bruxism.
Expert Opin Drug Saf. 2014;13(10):1319-26. doi: 10.1517/14740338.2014.947262.

17. Alencar MJS, Martins BMC, Vieira BN. A relação do bruxismo com a dopamina. Rev. bras. odontol., 2014; 71(1):62-66. http://revista.aborj. org.br/index.php/rbo/article/download/539/416

18. Abe K, Shimakawa M. Genetic and developmental aspects of sleeptalking and teeth-grinding. Acta Paedopsychiatr. 1966;33:339-344. https://www.ncbi.nlm.nih.gov/pubmed/5341985

19. Reding GR, Rubright WC, Zimmerman SO. Incidence of bruxism. J Dent Res. 1966;45:11981204.

https://www.ncbi.nlm.nih.gov/pubmed/5224088

20. Hublin C, Kaprio J, Partinen M, Koskenvuo M. Sleep bruxism based on self-report in a nationwide twin cohort. J Sleep Res. 1998;7:61-67. https://www.ncbi.nlm.nih.gov/pubmed/9613429

21. Rintakoski K, Hublin C, Lobbezoo F, Rose RJ, Kaprio J. Genetic factors account for half of the phenotypic variance in liability to sleep-related bruxism in young adults: a nationwide Finnish twin cohort study. Twin Res Hum Genet. 2012;15:714-719. doi: 10.1017/thg.2012.54

22. Lesh KP, Zeng Y, Reif A, Gutknecht L. Anxietyrelated traits in mice with modified genes of the serotonergic pathway. Eur. J. Pharmacol. 2003;480(1-3):185-204. https://www.ncbi.nlm. nih.gov/pubmed/14623362

23. Canli, T. \& Lesh, K. P. Long story short: the serotonina transporter in emotion regulation and social cognition. Nat. Neurosci., 10(9):11039, 2007. https://www.ncbi.nlm.nih.gov/pub$\mathrm{med} / 17726476$

24. Munafo MR, Freimer NB, Ophoff R, Veijola J, Miettunen J, Jrvelin M et al. 5-HTTLPR genotype and anxiety-related personality traits: a meta-analysis and new data. Am J Med Genet B Neuropsychiatr Genet. 2009;5;150B(2):27181. doi: 10.1002/ajmg.b.30808.

25. Morris-Rosendahl, D. J. Are there anxious genes?. Dialogues Clin. Neurosci. 2002;4(3):251-60.

https://www.ncbi.nIm.nih.gov/pmc/articles/ PMC3181683/

26. Lobbezoo F, van Denderen RJ, Verheij JG, Naeije M. Reports of SSRI-associated bruxism 
in the family physician's office. J Orofac Pain. 2001 Fall;15(4):340-6.

https://www.ncbi.nlm.nih.gov/pubmed/12400402

27. Abe $Y$, Suganuma T, Ishii M, Yamamoto $G$, Gunji T, Clark GT et al. Association of genetic, psychological and behavioral factors with sleep bruxism in a Japanese population. J Sleep Res. 2012;21:289-296. doi: 10.1111/j.1365-2869.2011.00961.x.

28. Portela A, Esteller M. Epigenetic modifications and human disease. Nat. Biotechnol. 2010; 28(10):1057-68, 2010. doi: 10.1038/nbt.1685.

29. Munafo MR, Clark TG, Moore LR, Payne E, Walton R, Flint J. Genetic polymorphisms and personality in healthy adults: A systematic review and meta-analysis. Mol. Psychiatry. 2003;8(5):471-84. https://www.ncbi.nlm.nih. gov/pubmed/12808427

30. Kundakovic M. Prenatal programming of psychopathology: The role of epigenetic mechanisms. J Med Biochem. 2013;32: 313-324. https://www.degruyter.com/view/j/jomb.2013.32. issue-4/jomb-2013-0047/jomb-2013-0047.xml
31. Calic A, Peterlin B. Epigenetics and bruxism: possible role of the epigenetics in the etiology of bruxism. Int J Prosthodont. 2015 ;28(6):594-9. doi: 10.11607/ijp.4126

32. Vanderas AP, Menenakou M, Kouimtzis $\mathrm{T}$, Papagiannoulis L. Urinary catrcholamine levels and bruxism in children. J Oral Rehabil. 1999;26(2):103-10. https://www.ncbi.nlm.nih. gov/pubmed/10080306

33. Takaoka R, Ishigaki S2, Yatani H, Ogata S3 Hayakawa K34Evaluation of genetic factors involved in nocturnal electromyographic activity of masticatory muscles in twins. Clin Oral Investig. 2017 ;21(1):319-325. doi: 10.1007/s00784016-1794-3.

34. Cruz-Fierro N, Martínez-Fierro M, Cerda-Flores RM, Gómez-Govea MA, Delgado-Enciso I, Martínez-De-Villarreal LE et al. The phenotype, psychotype and genotype of bruxism. Biomed Rep. 2018 Mar;8(3):264-268. doi: 10.3892/ br.2018.1041

Submetido em: 20-2-2018

Aceito em: 19-6-2018 